\title{
Entre(linhas) e pontos do teatro de Machado de Assis: o seu tempo no nosso tempo
}

\author{
Jussara Bittencourt de Sá*
}

\begin{abstract}
Resumo
A proposta deste texto é apresentar uma análise das concepções de nação e de nacionalidade em peças do teatro brasileiro no século XIX, em especial Quase Ministro, de Machado de Assis. Procura-se, em suma, evidenciar que o teatro machadiano cumpriu papel essencial para a representação/constituição da Nação, colocando em cena diferentes concepções sobre a própria nacionalidade, através das palavras, ambientações e representações dos tipos sociais que compunham a sociedade brasileira da época e que podem estar sendo reinscritas no atual contexto.
\end{abstract}

\section{Palavras-chave}

Machado de Assis. Teatro. Nação.

Nesta leitura procuro pontuar algumas reflexões acerca da importância da palavra na construção das concepções de nação que adentram a cena do teatro no Brasil no século XIX. Para tanto, focalizo as falas das personagens ditas "nacionais", e também as consideradas "estrangeiras", na tentativa de evidenciar como autores teatrais, em especial, Machado de Assis, na peça Quase Ministro, de 1863, através das personagens colocadas em cena, buscam representar a brasilidade através do mapeamento das diferentes classes sociais locais em sua interação com diferentes nacionalidades estrangeiras.

Ao direcionar este estudo para a literatura teatral brasileira, que possui oficialmente sua história inaugurada com as primeiras manifestações cênicas elaboradas pelos jesuítas, destaco, ainda, que, a partir do século XIX, com a afirmação gradativa do sentimento de nacionalidade, o teatro se consolida como forma de representação da identidade brasileira e estabelece com determinados segmentos sociais uma espécie de diálogo "civilizador". O que significa que os escritores da época apresentavam/possuíam, como característica, a promoção de um ideário do que se

\footnotetext{
" Doutora em Literatura pela UFSC. Professora do Programa de Pós-graduação em Ciências da Linguagem - UNISUL.
} 
desejava fosse o brasileiro, que registrasse e apresentasse os caminhos para a edificação do perfil do brasileiro.

A palavra no teatro, dizendo de outro modo, e no sentido do que Antonio Candido (1987, p. 27) afirma sobre a literatura brasileira em geral, mostrou-se absolutamente "empenhada", imaginando os autores, ao colocarem o Brasil em cena, muitas vezes em confronto com o "Outro", ou nele se retratando, estarem contribuindo efetivamente para a construção desse mesmo Brasil. Creio que o pensamento de Ítalo Calvino também contribui para orientar a reflexão que aqui se propõe. Calvino (1994, p. 8) comenta que "não se pode observar uma onda sem levar em conta os aspectos complexos que ocorrem para formá-la e aqueles também complexos a que dá ensejo". Neste sentido, o autor enfatiza a importância de se procurar compreender não só os elementos formadores, mas também os seus desdobramentos, tendo em vista as complexidades e peculiaridades inerentes ao processo de criação.

É por essa linha que de reflexões que percorro a idéia de nação representada pelas palavras das personagens na peça estudada, e como podem corresponder ao que pensa o autor ao representar conteúdo social, já que, de acordo com Bakhtin (1999, p. 36), a enunciação é o produto da interação de indivíduos socialmente organizados, pois sua natureza é social. Nesse caso, interessa pensar também se as palavras (nos diálogos das peças teatrais) podem ser associadas à concepção de Bakhtin, de que a enunciação não existe fora de um contexto sócio-ideológico, e, por isso, neste caso em particular, pergunta-se se o autor teatral anunciaria um "horizonte social" bem definido, pensado e dirigido a um auditório social também definido, de onde, pelo diálogo, se construiria um imaginário de uma determinada nação.

Conforme Bakhtin (1999, p. 36-37) toda enunciação completa é constituída de significação e de sentido. Esses dois elementos integram-se em um todo e sua compreensão só é possível na interação. Por isso procura-se, nesta leitura, observar como Machado de Assis engendra os diálogos, se há de fato um caráter dialógico nessas encenações, e, a partir daí, analisar como representam a sociedade através do texto, pois as falas de um personagem podem revelar diferentes dimensões do discurso hegemônico.

Neste sentido, cabe destacar o contexto histórico do século XIX, marcado pela Independência (1822), Abolição da Escravidão (1888) e pela Proclamação da República (1889). Tais acontecimentos tornam-se emblemáticos para se refletir sobre a enunciação da nacionalidade que se delineia na peça teatral Quase Ministro, de 1863.

Em Instinto de nacionalidade, Machado de Assis, referindo-se ao teatro brasileiro, justifica o pouco espaço que ele ocupa em seu texto, pois acredita não haver, naquela época, teatro brasileiro. Segundo Machado de Assis (1999, p. 31-32), quase não se escrevia e/ou representavam peças brasileiras. Em decorrência, na sua perspectiva, a discussão sobre o teatro brasileiro poderia "reduzir-se a uma linha de 
reticências". ${ }^{1}$ Entretanto, observa-se que Machado de Assis sinaliza, com essa referência, para a complexidade de interpretações e a continuidade que pode advir das reticências, tomando-se-as como um elemento passível de desdobramentos a posteriori. Em outras palavras, algo que não está acabado, mas em construção. Embora reconhecendo que o pouco relevo dado por Machado ao teatro em seu conhecido ensaio crítico possa ter contribuído para a relativa escassez de estudos sobre o teatro do século XIX na crítica local, foi tentando desvendar essa linha de reticências que elaborei a leitura das peças teatrais selecionadas.

Em seu texto "Idéias sobre o teatro", publicado na revista O Espelho, de 25 de setembro de 1859, Machado de Assis (1999, p. 204) comenta que "A arte dramática não é ainda entre nós um culto; as vocações definem-se e educam-se como resultado acidental. As perspectivas do belo não são ainda o ímã da cena". O autor declara que a arte teatral não recebia o valor que merecia, uma vez que não Ihe eram concedidos incentivos, e isso era evidenciado pelas limitações da produção teatral.

Machado de Assis (1999, p. 204) ainda deixa clara a preocupação sobre a limitação e a redução da arte teatral ao "foro de uma Secretaria de Estado", ou seja, às limitações do Conservatório Dramático, ${ }^{2}$ que para ele atuava como o corpo de polícia, "censura e pena".

De acordo com João Roberto Faria (2001, p. 101), Machado condena as peças românticas que se afastam da realidade e defende um teatro "com alcance moralizador, voltado para a reprodução da vida social em cena".

Neste sentido, a produção teatral de Machado de Assis marca por mostrar, além de outros, um mapa da estrutura simbólica da política brasileira. A peça Quase Ministro, publicada em 1863, é uma comédia realista, em ato único, foi escrita especialmente para ser representada em um sarau literário e artístico em 22 de novembro de 1862, na casa de alguns amigos de Machado de Assis, que residiam à rua da Quitanda. A ação se passa no Rio de Janeiro e é ambientada na casa da personagem Luciano Martins (ASSIS, 1982, p. 130).

As personagens que compõem a peça são: Luciano Martins, Deputado; Dr. Silveira; José Pacheco; Carlos Bastos; Mateus; Luiz Pereira; Muller; Agapito.

O enredo é inaugurado com as palavras de Silveira a Martins, comentando sua atração por cavalos. Martins avisa ao amigo que está para ser indicado como Ministro.

Assim, em um ambiente burguês, na casa de Martins, dentro de uma trama linear, Machado sustenta a ação pela palavra. Os diálogos vão apresentando as

\footnotetext{
1 No entanto, mesmo tendo dado pouco espaço à crítica teatral, Machado exclui desse contexto, dentre outros, dramas de Gonçalves de Magalhães, Gonçalves Dias e José de Alencar, e as comédias de Martins Pena, que ele considerava com "talento sincero e original".

2 Sobre o Conservatório Dramático, Machado afirma que ser uma forma de censura, um aparelho político de intervenção na arte dramática. Tal categoria política existiu, e isto revela que para Machado a criação de um campo estético - como produção de subjetivação nacional precisava da atuação das forças intelectuais moleculares em aliança com a força intelectual dos aparelhos políticos estatais. O Conservatório não poderia existir como uma máquina patrimonialista ou como uma máquina moral de repressão da narrativa dramática; ela teria que funcionar como uma força de agenciamento qualitativo do trabalho estético. No entanto, entre 1862 e 1864, o Conservatório Dramático, o órgão censor, vai receber a colaboração de Machado.
} 
personagens Luciano Martins, deputado; Dr. Silveira, primo de Martins; José Pacheco, um escritor de artigos; Carlos Bastos, poeta; Mateus, um inventor; Luiz Pereira, alguém cujos filhos têm Ministros como padrinhos; Müller, estrangeiro; Agapito, empresário das artes, amigo de Müller.

Ainda que a peça possua como fulcro Martins, que está cotado para se tornar ministro, o foco maior é dirigido aos interesseiros - um cronista político, um inventor, um poeta, e um empresário de teatro, estrangeiro - que o assediam, com a intenção de conseguir cargos e favores.

$\mathrm{Na}$ seqüência, outras personagens vão sendo acrescidas à trama. Elas comungam do mesmo objetivo de José Pacheco: obter algum proveito através da bajulação. Um exemplo é Mateus, que se diz inventor, e oferece uma peça de artilharia ao quase ministro.

Na cena VII, Mateus apresenta seu invento:

\begin{abstract}
- A minha idéia é simples como água. Inventei uma peça de artilharia... É um invento que põe na mão do país que o possuir a soberania do mundo. Eu pretendo denominá-la: $O$ raio de Júpiter, para honrar com um nome majestoso a majestade do meu invento. Devo acrescentar que alguns ingleses, alemães e americanos, que, não sei como, souberam deste invento, já me propuseram ou a venda dele, ou uma carta de naturalização nos respectivos países: mas eu amo a minha pátria e os meus ministros. (1982, p. 145)
\end{abstract}

Através da fala desta personagem, ao anunciar possuir o domínio da técnica para construir uma máquina mirabolante, o raio de Júpiter, ${ }^{3}$ Machado evidencia o espírito cientificista que transitava na sociedade da época, ou seja, o mito da técnica que se reitera a partir da possibilidade do novo, do poder. O domínio da técnica e/ou a produção de tal máquina aparece como fetiche (o que é feito, não natural, que exerce fascínio); a anunciada perfeição do raio de Júpiter se vincula ao desejo e à deificação da máquina. Machado, de forma irônica, já a partir do nome, coloca o raio de Júpiter como um instrumento que ao mesmo tempo em que pode assombrar, também pode promover o poder de quem o detém: o poder dos deuses nas mãos dos homens.

A propósito, Frederic Jameson (1996, p. 64) afirma que o fetiche contemplaria um ato simbólico cujo horizonte é o destino da comunidade, trazendo sempre as marcas de sua função de compromisso pela qual oferece uma resolução imaginária para contradições reais recalcadas. O fetiche da máquina tende a incorporar, mais do que nunca, a dimensão estranhada de sociabilidade. A máquina aparece como o ente da dominação, o estranho familiar. Ela possuiria, em si, a promessa da mediação plena da sociabilidade humana.

Outro aspecto significativo é apresentado por Helena Tornquist (2002, p. 224) ao considerar que, "A alusão à força a ao poder, contida na designação Raio de Júpiter, provoca efeito contrário, acentuando a desmedida da proposta: a ênfase tem como efeito imediato a diminuição." Daí a ironia desta "nova ciência" que diminui a própria nação e que pode conceder poderes aos mortais.

3 Machado recorre à mitologia em vários momentos da peça como também nas expressões na cena IV, na qual Silveira comenta: "(baixo) - Não é possível, este conhece o Pégaso. Com licença". 
O que importa, segundo a personagem Mateus, é sua legitimação pelas grandes nações, através da suposta compra ou de naturalização de seu invento. As nações estrangeiras, especialmente as imperialistas - a Inglaterra, a Alemanha e os Estados Unidos - são utilizadas como referência para dar credibilidade a sua invenção.

Na cena XI, a personagem Agapito solicita do "quase ministro" uma subvenção para contratar o teatro lírico italiano, pois, segundo ele, a música seria uma das artes que caracterizariam o refinamento de um povo, e a italiana seria a mais refinada, como se pode observar no diálogo entre a referida personagem e o estrangeiro, Sr. Müller, intermediado por Silveira:

AGAPITO - Apresento-te o Sr. Müller, cidadão hanoveriano.

SILVEIRA (a Müller) - Queira sentar-se.

AGAPITO - O Sr. Müller chegou há quatro meses da Europa e deseja contratar o teatro lírico.

SILVEIRA - Ah!

MÜLLER - Tenho debalde perseguido os ministros, nenhum me tem atendido. Entretanto, o que eu proponho é um verdadeiro negócio da China.

AGAPITO (a Müller) - Olhe que não é ao ministro que está falando, é ao primo dele. MÜLLER - Não faz mal. Veja se não é negócio da China. Proponho fazer cantar os melhores artistas da época. Os senhores vão ouvir coisas nunca ouvidas. Verão o que é um teatro lírico. (1982, p. 144)

A personagem Mateus entra em cena como uma espécie de contraponto:

- Não é má; e os talentos do país? Os que tiveram à custa do seu trabalho produzido inventos altamente maravilhosos? O que tiver posto na mão da pátria a soberania do mundo? (1982, p. 148)

Agapito, defendendo o propósito de refinar a arte brasileira, interpola:

- [...] Se um país é feliz, é bom que ouça cantar, porque a música confirma comoção da felicidade. Se o país é infeliz, é também bom que ouça cantar, porque a música adoça as dores. Se é dócil, é bom que ouça música, para nunca se lembrar de ser rebelde. Se um país é rebelde, é bom que ouça música, porque a música adormece os furores, e produz a brandura. Em todos os casos, a música é útil. Deve ser até um meio de governo (1982, p. 148).

Muitos elementos significativos emergem destas palavras. Primeiramente, o interesse do brasileiro Agapito em promover o empresário alemão e a arte estrangeira. Na seqüência, há um confronto de idéias, que gera uma discussão sobre o elenco de valores da sociedade da época. Também se observa que, especialmente nessa última fala, a música aparece como fantasmagoria de acordo com a definição de Walter Benjamin (1991, p. 62-62) para o produto cultural que "hesita ainda um pouco antes de se tornar mercadoria pura e simples". ${ }^{4}$ Agapito, ao mesmo tempo em que concede à

\footnotetext{
${ }^{4}$ Segundo Walter Benjamim, cada inovação técnica que rivaliza com uma arte antiga assume algum tempo a forma da fantasmagoria.
} 
música um poder mágico, anestésico, que transita à sombra e é capaz de modificar ou instaurar diferentes situações, Ihe confere o aspecto utilitarista de mercadoria, ou seja, a utilização política para essa arte. Para a personagem, portanto, o poder e a utilidade estão contidos na música italiana, na arte estrangeira que precisa ser utilizada como meio civilizador.

Em Quase Ministro, além da personagem Müller, as nações estrangeiras são trazidas à cena em vários momentos. Machado ironiza a parcela da sociedade brasileira que exalta o estrangeiro. Tal fato não ocorre apenas nas falas que glorificam a cultura do estrangeiro, a sua arte, mas também pela credibilidade e superioridade atribuídas às nações imperialistas, tidas como modelares pelos personagens brasileiros e pelo estrangeiro.

Na cena II, por exemplo, Machado anuncia como a cultura brasileira vai concedendo lugar aos políticos. Ao chegar à casa de Martins, José Pacheco, ${ }^{5}$ cronista político que diz assinar seus artigos com o pseudônimo de Armand Carrel, procura mostrar os princípios de sua profissão, comentando com o anfitrião:

\begin{abstract}
- Vossa excelência dá-me licença?... Em política ser lógico é ser profeta. Apliquemse certos princípios a certos fatos, a conseqüência é sempre a mesma. Mas é mister que haja os fatos e os princípios... É o que Ihe digo. Depois dos meus artigos, principalmente o $\mathrm{V}$, não é lícito a ninguém recusar uma pasta, só se absolutamente não quiser servir o país. Mas, nos meus artigos está tudo, é uma espécie de compêndio. Demais porque a situação é nossa; nossa, repito, porque sou do partido de vossa excelência. [...] O que eu pergunto é se pretende governar com energia ou com moderação. Tudo depende do modo. A situação exige um, mas o outro também pode servir... Sim, a energia é isso, a moderação, entretanto... (mudando de tom)... O que nunca me aconteceu foi atacar ninguém; não vejo as pessoas, vejo as idéias. Sou capaz de impugnar hoje um ato de um ministro e ir amanhã almoçar com ele. (1982, p. 138)
\end{abstract}

Seu discurso constitui, idealmente, um território de interlocução, onde se confrontam diferentes fontes de informação. Explicitamente, Machado coloca em evidência os textos publicados em jornais. Ao inserir José Pacheco, o cronista de textos prontos com discursos moldáveis, Machado ironiza, também, a consistência do discurso de órgãos da grande imprensa, enquanto interlocutores nas relações da nação. Na fala aparece, não só o interesse, mas também a vontade de negociação. Neste sentido, na perspectiva de Machado, tudo, na esfera política, pode ser adequado, manipulado.

No decorrer da referida cena, Silveira alerta seu primo Martins para os problemas que terá com bajuladores, mesmo sendo ainda um "quase ministro". Martins comenta que "- tal preço não valeria o trono" (1982, p. 140). A fala de Martins revela, portanto, que a personagem demarca um limite para a aceitação do cargo. Ele demonstra não estar corrompido pela aura do poder que o cargo ostenta. Há, nas

5 Remeto ao estudo realizado por Helena Tornquist, que afirma que o elogio aos próprios discursos e a utilização do pseudônimo Armand Carrel podem ser vistos como uma ironia do escritor "ao afrancesamento da sociedade brasileira de sua época", e também por ser Armand Carrel um importante e sério jornalista, mas este nome, no texto, é usado para "nomear um indivíduo de características opostas". (TORNQUIST, 2002, p. 225). 
palavras desta personagem, a anunciação de ideais que norteariam sua tolerância à aceitação do cargo. Presencia-se, neste fato, a sugestão de Machado que nem tudo, ou melhor, nem todos são corrompíveis, pois ainda restam alguns com bons princípios na sociedade.

Em Quase Ministro, a nação e a nacionalidade se aproximam de um conceito de nação como constitutivo sociológico-político, na medida em que as personagens representam somente segmentos da elite social. Percebe-se, também, que após décadas da Independência, o enredo coloca, em cena, os brasileiros no comando político. No entanto, eles se mostram dissimulados no trato das questões que envolvem o poder no/e do Estado: são indivíduos que agem em busca de seus próprios interesses, não importando quão absurdo possa ser o viés proposto para obtê-los, buscando somente obter proveito do Estado, embora o discurso seja o do interesse público e o do bem comum. Excetuando Martins, o Estado é visto pelos demais, em Quase Ministro, como algo de onde se pode tirar proveito. Tal fato, que emerge do enredo, traz à tona a dissimulação da elite que comanda a nação brasileira. Portanto, Machado, nesta peça, denuncia as fraturas no alicerce da nação em processo de construção da sua identidade.

Neste aspecto, verifica-se que há um confronto entre alguns que valorizam o brasileiro, outros, o estrangeiro. Excetuando as personagens Martins e Silveira, as outras são mostradas como personas de índole duvidosa. Conforme afirma Schwarz (1997, p. 16), Machado procura ressaltar, em Quase Ministro, personagens que pretendem obter favores, colocando em cena a ação de diferentes tipos de parasitas na sociedade.

Na penúltima cena, quando estão todos reunidos, Martins anuncia que não será mais ministro. Os especuladores vão embora, restando apenas Martins e Silveira. $\mathrm{Na}$ cena final, Martins e Silveira, sozinhos, comentam:

MARTINS - Que me dizes a isto?

SILVEIRA - Que hei de dizer! Estavas a surgir... dobraram o joelho: repararam que era uma aurora boreal, voltaram as costas e lá se vão em busca do sol... São especuladores!

MARTINS - Deus te livre destes e de outros...

SILVEIRA - Ah! livra... livra. Afora os incidentes como o de Botafogo... ainda não me arrependi das minhas loucuras, como tu lhes chamas. Um alazão não leva ao poder, mas também não leva à desilusão (1982, p. 150).

Martins parece conformado com o desenrolar dos fatos. A desilusão com as atitudes de seus convivas mostrou-lhe o cerco de interesseiros que envolvem os políticos. Silveira, por sua vez, reafirma sua descrença na política, preferindo o convívio com os cavalos. Ao apresentar tal associação, Machado, através dessas imagens, não só denuncia os problemas nas relações políticas do seu tempo, mas os valores vigentes na sociedade do nosso tempo, o que tornam as palavras na obra de Machado de Assis cada vez mais atuais...

\section{Referências}


ASSIS, Machado de. Instinto de nacionalidade e outros ensaios. Porto Alegre: Mercado Aberto, 1999.

. Idéias sobre Teatro. In: Obras completas de Machado de Assis: Críticas literárias/Críticas Teatrais. São Paulo: Formar, 1989.

O Conservatório Dramático. In: Obras completas de Machado de Assis: Críticas literárias/Críticas Teatrais. São Paulo: Formar, 1989.

Quase Ministro In: MARINHO, Teresinha et alii. (Org) Clássicos do teatro brasileiro: Machado de Assis. Vol: 6. Rio de Janeiro: FUNARTE, 1982.

BAKHTIN, Mikhail. Marxismo e Filosofia da Linguagem. São Paulo: Hucitec, 1999. CALVINO, Ítalo. Palomar. São Paulo: Companhia das Letras, 1994.

CANDIDO, Antonio. Formação da literatura brasileira: momentos decisivos. Vol. I (1750-1836). Belo Horizonte: Itatiaia, 1987.

FARIA, João Roberto. Idéias teatrais: o século XIX no Brasil. São Paulo: Perspectiva, 2001.

JAMESON, Frederic. Pós-Modernidade: a lógica cultural do capitalismo tardio. São Paulo: Ática, 1996.

SÁ, Jussara B. de. A Nação em cena: Brasil, Teatro, Século XIX. Florianópolis: Editora da UFSC, 2010.

SCHWARZ, Roberto. Ao vencedor as batatas. São Paulo: Editora 34, 1997.

TORNQUIST, Helena. As novidades velhas: o teatro de Machado de Assis e a comédia francesa. São Leopoldo: UNISINOS, 2002.

\section{Title}

Inter(lineations) and points of Machado de Assis's Drama: His Time in Ours

\section{Abstract}

The proposal of this text is to analyze the conceptions of nation and nationality in Brazilian plays of the 19th century, especially the one called Quase Ministro (Almost Minister) by Machado de Assis. In short, evidence is sought to demonstrate that Machado's theater has fulfilled an essential role in the representation/constitution of the Nation, placing on the stage different conceptions of nationality, through the creation of favorable surroundings, speeches, and representations of the social types that formed the Brazilian society of that time.

\section{Keywords}

Machado de Assis, theater, nation.

Recebido em 25.06.2011. Aprovado em 04.07.2011. 